\title{
A Comparison of the Performance of Brand- Affiliated and Unaffiliated Hotel Properties
}

\author{
Steven A. Carvell', Linda Canina', and Michael C. Sturman'
}

\begin{abstract}
Research has shown that performance differences exist between brand-affiliated hotels and unaffiliated properties. However, the extant empirical results are mixed. Some research has shown that brands outperform unaffiliated hotels on various metrics, whereas other research has shown the opposite. This article analyzes this issue using a matched-pair approach where we compare the performance differences of brand-affiliated and unaffiliated properties between 1998 and 2010. The matched-pair approach ensures that local competitive conditions as well as hotel characteristics are the same across the comparison pair. In addition, all potential omitted-variable bias and model misspecifications are avoided. Thus, to address our research question, we compare branded hotels with unaffiliated properties that are identical in age, market segment, location, and duration of operation, as well as having a similar number of rooms. Our analysis shows that performance differentials are present, albeit not systematic. We found no consistent advantages in all segments for either the affiliated hotels or the comparable unaffiliated properties, taking into account our comparison factors. That said, the methodology of our approach yields results that are more informative to the affiliation choice of owners and to the growth strategies of hotel brand-owner companies than those of previous empirical studies.
\end{abstract}

\section{Keywords}

finance; corporate development; marketing and sales; strategic management

Few observers would dispute the prominent position of branding strategies in the contemporary hotel industry. The multitude of hotel brands has provided a common vehicle for both the individual hotel owner and brand-owning lodging companies to foster growth and wealth creation. As brand affiliation is an alliance, it is essential that value is created for each of the deal's participants.

Decades of research studies have demonstrated that successful brands provide consumers with a variety of functional and emotional benefits that promote their perceptions and subsequent behavior related to that brand, and it has been shown that such brands can be important intangible company assets with a demonstrable financial value (Keller, 2002). The view that a brand has a value to both consumers and brand-owning companies has materialized in the concept of brand equity (Aaker, 1991). Brand equity helps to offset competition by differentiating the product, allowing brand owners to charge a premium, and fostering customer loyalty (Aaker, 1991). Many have claimed that the enhancement of the brand's value is critical to successful brand management (Aaker, 1991, 1996; Kapferer, 1997; Keller, 1998). Prasad and Dev (2000), for instance, argue that brand equity is a key determinant of success within the hotel industry. Empirical evidence exists to support their proposition. As one example, Kim and Kim (2005) show a significant positive relationship between brand equity and sales within the luxury segment of the hotel industry.

Assuming that a brand has value to both consumers and brand owners through offsetting competition, price premiums, and customer loyalty, it follows that prices, capacity utilization, and revenue for brand-affiliated hotels ought to exceed those of their unaffiliated counterparts. However, the empirical results for this inference are mixed. We have seen evidence showing the following benefits of brands: Branded hotels have higher survival rates than unaffiliated hotels (Ingram \& Baum, 1997), the revenue per available room (RevPAR) index of unaffiliated limited-service hotels that convert to a brand affiliated improves (Love, Walker, \& Sutton, 2012), performance improvements occur for hotels that rebrand to a higher market segment (Hanson, Mattila, O'Neill, \& Kim, 2009), and brand-affiliated hotels have significantly higher average occupancy rates than unaffiliated hotels (O’Neill \& Carlback, 2011). However, we have also seen a study showing that unaffiliated hotels have

'Cornell University, Ithaca, NY, USA

\section{Corresponding Author:}

Linda Canina, School of Hotel Administration, Cornell University, 448 Statler Hall, Ithaca, NY 14853, USA.

Email: Ic29@cornell.edu 
significantly higher average daily room rates (ADRs) and average RevPAR (O'Neill \& Carlback, 2011).

The broad spectrum of opinions and conflicting findings on this topic calls for a more comprehensive study of the performance of branded hotels in comparison with unaffiliated hotels. This is due to the fact that the extant empirical evidence is inconsistent (as we just outlined), is often limited in scope, and does not analyze performance differences of direct competitors that are similar in characteristics and are subject to the same competitive conditions in the same local market.

This is the first empirical study of a sample of hotels analyzed over a lengthy time horizon that uses a matchedpair approach to compare affiliated hotels with comparable unaffiliated properties. These paired hotels opened in the same year and in the same location, compete in the same market segment, and are similar in size, as measured by the number of rooms available. This approach ensures a valid comparison of these properties' performance ratios. The demand generators, local market economic conditions, competitive and agglomerative factors, and general condition and characteristics of the paired hotels are the same across the comparison hotels by sample construction. This article analyzes three measures of performance differences between branded and unaffiliated hotels, namely, ADR, occupancy rate, and RevPAR, using a sample of 212 matched pairs that encompass 2,473 matched property years from 1998 through 2010.

Analyzing these data allows us to address several questions of significant importance to investors as well as to brand-owning companies. Do branded hotels systematically outperform unaffiliated hotels? If there are statistically significant performance differences, are they segment or market dependent? What inferences can be drawn from the performance patterns that would inform us further about the idiosyncrasies facing hotel owners when deciding between brand affiliations or opening an unaffiliated hotel? These questions among others are addressed below.

\section{Literature Review}

A fundamental decision for hotel developers and owners is whether it is best to contract with a brand and open a branded hotel or whether it is best to go it alone and open an unaffiliated hotel. Similarly, every brand-owning corporation is faced with the decision to grow through the expansion of hotels within existing brands or to extend their current family of brands and develop a new brand to serve another market niche.

As in all economic decisions, the choice of the corporate brand owner and the hotel owner depends upon the expected benefits relative to the expected costs. The estimation of these costs and benefits is not a trivial task due to the existence of both direct and indirect effects. There are theoretical arguments that imply that branded hotels ought to outperform unaffiliated hotels due in part to a brand's reputation, distribution, and operational consistency (Lafontaine, 1992). However, there are theoretical arguments that imply the opposite, notably, potential agency conflicts, transaction costs, knowledge resources, and market failures (Combs \& Ketchen, 1999). The challenge in these contrasting arguments lies in determining the magnitude of these two opposing factors for a given property or project.

It has been argued that a brand is more than a product. The physical components and the intangible attributes of a hotel brand may be important considerations to the consumer (de Chernatony \& McDonald, 2003). These additional attributes or "added values" distinguish a brand from a product (de Chernatony \& McDonald, 2003; Doyle, 2002; Jones \& Slater, 2003). These added values play an important role in many consumers' purchase decisions, as brands are bought for emotional reasons as well as purely functional reasons (Doyle, 2002). Jones and Slater (2003) argue that the added values are those that come from experience of the brand, such as familiarity, reliability, and reduction of risks; those that come from the people that use the brand, characterized by associations consumers have of the brand; those that come from a belief that the brand is effective; and those emanating from the appearance of the brand. Brands have been shown to benefit the companies that form alliances with the brand-owning corporations. These companies can achieve competitive advantage by generating consumer loyalty to the brand, having less vulnerability to the marketing actions of competitors, increasing effectiveness of marketing communication activity, achieving greater profit margins than competitors, and creating additional brand extension opportunities (Keller, 2002). It has also been shown that brands garner price premiums in the marketplace (Anselmsson, Bondesson, \& Johansson, 2014; Steenkamp, Van Heerde, \& Geyskens, 2010). Assuming these benefits extend to the hotel industry, we would expect to see ADR premiums and capacity utilization advantages consistently accruing to affiliated hotels.

Under the franchising model, individual owners license the brand's business model: the right to use its brand name and trade dress, as well as access to its marketing strategies, organizational synergies, and operating routines. In this arrangement, owners purchase both strategic and operational support from the franchisor. In return for access to a proven business system, the franchisee pays the franchisor royalties that include an initial fee and a percentage of revenue or profit, along with a host of other ancillary fees and system reimbursable expenses associated with marketing and operating the family of brands. In a recent study, the average franchising fees charged in the full-service segment of the market ranged from about $7 \%$ to more than $14 \%$ of total revenues (HVS, 2014, Fall). 
In particular, brand-owning corporations sell immediate customer recognition for a new or converted property. The purchase of brand affiliation provides an immediate reputation, which is a key method for attracting new customers and should assist in retaining current customers (Keller, 1993). Brand is a recognized signal to the customers that conveys a certain level of quality and service. As a result, brands reduce customers' risk and uncertainty, and branding reduces customers' search costs (Washburn, Till, \& Priluck, 2004; Zeithaml, 1988). It has been shown that customers respond positively to brand familiarity (Alba \& Hutchinson, 1987; Brooking, 1997; Washburn et al., 2004). Also, the presence of a brand reduces customers' price sensitivity and encourages purchase decisions, with a result of improving a firm's revenues and equity value (Lane \& Jacobson, 1995; Srivastava, Shervani, \& Fahey, 1998).

In terms of the benefits that might accrue to hotel owners that choose brand affiliation, the literature suggests that hotel brand equity should be a strong motivating factor in this decision. A positive relationship has been identified between brand equity and the financial performance of the brand-owning company (Kim, Kim, \& An, 2003). Many have claimed that the enhancement of the brand's value or equity is critical to successful brand management (Aaker, 1991, 1996; Kapferer, 1997; Keller, 1998). We already alluded to the argument by Prasad and Dev (2000) that brand equity is a key determinant of success within the hotel industry and Kim and Kim's (2005) study showing a positive relationship between brand equity and sales within the luxury segment of the hotel industry.

The mechanism of brand value creation remains under study. Several studies have focused on issues relating to how branded hotels gain advantage in customer satisfaction and distribution channel management. However, the body of work in this area draws mostly from the marketing literature related to brand advantages in consumer goods and services (Keller \& Lehmann, 2003; Krishnan \& Hartline, 2001; Murray \& Schlacter, 1990; Zeithaml, Parasuraman, $\&$ Berry, 1985). Within the hotel sector specifically, research has indicated that branded hotels that have higher levels of guest satisfaction can translate this advantage into higher average daily rates and occupancies (O'Neill, Mattila, \& Xiao, 2006). This suggests that there can be a motivation to brand a hotel to seek higher rates and occupancies. There is some evidence that under most circumstances, branded hotels have a higher survival rate than unaffiliated hotels (Ingram \& Baum, 1997). These results suggest that a performance advantage accrues to branded hotels that would lead to lower failure rates.

A relatively recent analysis examined a set of branded limited-service hotels in Texas of which one set converted from unaffiliated hotels and another set dropped their affiliation (Love et al., 2012). Overall, conversions from unaffiliated hotels to branded hotels yielded a within-market and a within-segment advantage, as evidenced by each hotel's RevPAR index, which is measured by dividing a sample hotel's RevPAR by its market segment's RevPAR. This result implies that branded limited-service hotels should generally outperform unaffiliated limited-service hotels. Due to methodological and sample limitations, though, such as analyzing hotels within a tight service category range over a short performance period, this particular set of results may not be generalizable. However, if Love et al.'s results are evident in a larger longitudinal sample, then we would expect to find that the performance of branded hotels exceeds that of unaffiliated hotels.

O'Neill et al. (2006) showed that brands affected the market value of mid-price and upscale hotels beyond the usual contribution attributed to net operating income (NOI) and RevPAR. Hanson et al. (2009) found performance improvements for hotels that rebranded to a higher market segment. Both studies support the proposition, discussed in detail later, that brand strength may not be uniform across market segments.

As we noted above, more than one study has found that unaffiliated hotels have significantly higher average daily rates than brand-affiliated hotels regardless of property size (Damonte, Rompf, Bahl, \& Domke, 1997). This was confirmed in a study that is most similar to our analysis. O'Neill and Carlback (2011) used a large sample of branded and unaffiliated hotels over the 2002-2008 economic cycle. They found that branded hotels had significantly higher average occupancy than unaffiliated hotels, whereas unaffiliated hotels had both significantly higher average ADRs and RevPARs, both over the entire period and on a year-byyear basis.

Needless to say, the local competitive landscape of a hotel strongly influences its performance. Factors to take into account here are hotel density as well as product homogeneity versus heterogeneity. These have been shown to affect the relative strength of agglomeration and competition effects. Freedman and Kosová (2012) revealed that the agglomeration benefits from co-location vary across hotels in different product segments, and new hotels are more likely to choose an area with a higher concentration of hotels in other segments to seek greater product differentiation. To achieve agglomeration benefits, incumbents must respond appropriately to competitive moves. It has been shown that awareness of competitive relationships, as well as competitors' initiatives, motivations, and capability to act or to respond (Chen, 1996; Chen, Su, \& Tsai, 2007; Smith, Ferrier, \& Ndofor, 2001), influence a firm's ability to compete dynamically. Furthermore, the brand equity literature proposes that brand affiliation helps to offset competition and builds customer loyalty (Aaker, 1991), achieves competitive advantage, reduces the effects of marketing actions of competitors, increases the effectiveness of marketing communication activity, and achieves greater profit 
margins than competitors (Keller, 2002). As a result, performance differences may exist between affiliated and unaffiliated hotels across market segments and market types due to variations in consumer behavior across hotel market segments (Blal \& Sturman, 2014; Zhang, Ye, \& Law, 2011), and in affiliated versus unaffiliated hotels' awareness of competitive relationships, competitors' initiatives, motivations, and capability to act or to respond (Chen, 1996; Chen et al., 2007; Smith et al., 2001). Regarding the hotel's capability to respond to competitive moves, assuming that brand-owning corporations have more experience and more resources than unaffiliated owners, affiliated properties ought to be better able to compete dynamically by responding appropriately to competitive moves through the assistance of the experienced brand-owning corporation.

\section{Data Sample and Method}

STR Global, an independent research organization that collects and collates hotel property data for hotels worldwide, supplied monthly hotel-level data for hotels in the United States for the period 1998-2010. The STR data consisted of monthly rooms sold, room supply, and room revenue by property. In addition, STR supplied categorical variables that describe some of the characteristics of each hotel. These data included (a) the number of rooms in each hotel, (b) the location type of the hotel (which could be urban, suburban, airport, highway, or resort), (c) the geographic region of the hotel, (d) the market location, (e) whether the property is brand affiliated, (f) the product and service quality segment category of the hotel, and $(\mathrm{g})$ the year the property opened.

The key variables of interest in this study, other than whether the property is brand affiliated, are the ADR, occupancy percentage, and RevPAR. Each of these variables was computed by property by year. To reduce the effects of seasonal fluctuations, we aggregated STR's monthly rooms data to arrive at the annual number of rooms sold, annual number of rooms available, and annual room revenue for each property for each year. This also addressed irregularities that may have occurred in a particular month that are not representative of the properties' performance (Ismail, Dalbor, \& Mills, 2002). Properties that had less than 12 months of data were eliminated from the sample. For these annualized measures, ADR is defined as annual rooms revenue divided by annual rooms sold. Occupancy is defined as annual rooms sold divided by annual rooms available (multiplied by 100 to create a percentage). RevPAR is defined as annual room revenue divided by annual rooms available.

This sample consists of brand-affiliated properties and unaffiliated hotels of various ages, sizes, and market segments, operating in 162 geographical markets. We used an indicator variable to classify whether the property is associated with a brand (value of 1) or not (value of 0 ). We computed age as the difference between the sample year and the year the property opened for operation. The size variable is simply the number of rooms in the hotel. The local market and the market segment were supplied by STR, which defines local U.S. markets as a Metropolitan Statistical Area (MSA) or a group of counties. STR's five market segments for each local MSA are determined by average room rates as follows: luxury (top 15\% average room rates), upscale (next 15\% average room rates), mid-price (middle $30 \%$ average room rates), economy (next $20 \%$ average room rates), and budget (lowest $20 \%$ average room rates). In rural or nonmetro markets, STR collapses the luxury and upscale segments into the upscale and forms the following four price segment categories: upscale (top 30\% average room rates), mid-price (next 30\% average room rates), economy (next $20 \%$ average room rates), and budget (again, the lowest $20 \%$ average room rates). Following the taxonomy design of Drennan and Kelly (2010), we segment the various markets included in the STR data into primary and non-primary markets.

We applied these distinctions to our matched-pair sample. We see the matched-pair approach as the most appropriate to analyze the performance of affiliated and unaffiliated hotels with the same characteristics and market conditions (Heckman, Ichimura, \& Todd, 1997, 1998). The matched-pair approach avoids omitted-variable bias along with misspecification biases due to nonlinearities.

Our sample consists of a matched set of branded and unaffiliated properties that opened in the same year, operated in the same local market, were categorized in the same market segment, were similar in size, and provided data for each year throughout the period from which it opened through 2010. For each unaffiliated property that opened in a given year, we selected one brand-affiliated property that met the above specifications. This resulted in 212 matched pairs yielding observations for 2,473 matched property years. By construction, age, market segment, and location, for the brand-affiliated and unaffiliated matched pair is exactly the same. The only hotel characteristic that unavoidably differed is the number of rooms. ${ }^{1}$ In short, we sought to ensure that each unaffiliated property is comparable with the branded property on the relevant attributes. For the matched pairs, $t$ tests were used to test the statistical significance of the mean difference, where the standard errors were adjusted for correlation within each matched pair using the Newey-West procedure (Newey \& West, 1987) modified for use in a panel data set using the procedure of Williams (2000). Levene's test was used to test the homogeneity of variances across the different matched-pair sets.

\section{Results}

In keeping with previous studies, our results were mixed, as shown in Exhibit 1. Unaffiliated properties outperformed affiliated hotels on average by US\$12.54 in ADR, whereas 
Exhibit 1:

Test of Mean Difference in ADR, Occupancy, and RevPAR for Brand-Affiliated and Unaffiliated Hotel Properties.

\begin{tabular}{lccc}
\hline \multirow{2}{*}{$N$} & \multicolumn{3}{c}{ Mean Difference, Unaffiliated - Affiliated } \\
\cline { 2 - 4 } & ADR & Occupancy & RevPAR \\
\hline 2,473 & US\$12.54*** & $-5.88 \% * * * *$ & US $\$ 2.05$ \\
\hline
\end{tabular}

Note. The standard errors used to compute the test statistics and significance levels were adjusted for correlation within each matched pair using the Newey-West procedure (Newey \& West, 1987) and modified for use in a panel data set using the procedure of Williams (2000). ADR $=$ average daily room rate; RevPAR = revenue per available room.

$* * * p<.001$.

affiliated properties had an average occupancy rate advantage of $5.88 \%$ above that of unaffiliated properties. Each of the average differences is significant at least at the $1 \%$ level. Given the divergent ADR and occupancy figures, it should not be a surprise that the average difference in RevPAR across the two groups was not statistically different from zero.

To consider the differences in the net effect of competitive and agglomeration factors across market segments and market type as well as the documented differences in the impact of brand on market segment, we categorized the matched-pair sample according to the five market segment groups and the two market type groups simultaneously. For each of these 10 groups, we tested the significance of the average difference between unaffiliated and affiliated ADR, occupancy rate, and RevPAR.

As shown in Exhibit 2, the sample-wide differences in ADR and occupancy rate do not necessarily carry over to each scale segment. Instead, we see considerable variation when hotels are categorized according to both market segment and market type. With regard to occupancy, we can see that across both the nonprimary and primary markets, brand-affiliated hotels have a fairly consistent and statistically significant occupancy rate advantage. This advantage ranges from a high of $8.54 \%$ among hotels in the primary upscale market to a low of $5.04 \%$ among luxury hotels in nonprimary markets. The sole exception to the occupancy rate advantage for branded hotels is within the luxury segment in primary markets, where there is no statistical difference between the occupancy rate of brand-affiliated and unaffiliated hotels.

The results regarding rate advantages show greater diversity by market segment and market type. Unaffiliated hotels produce significantly higher ADRs in the mid-price and upscale segments, but only in nonprimary markets. Among luxury hotels in nonprimary markets, the ADRs for unaffiliated hotels are not significantly different from those of brand-affiliated hotels. Also, across all segments in primary markets, brand-affiliated hotels and unaffiliated hotels have ADRs that are statistically indistinguishable. Regarding RevPAR, only brand-affiliated upscale hotels significantly outperform unaffiliated upscale hotels in primary markets (probably due to occupancy differences). No other RevPAR advantages exist.

Taken together, these results show the complexity of generalizing about the advantages of brand affiliation versus the benefits of remaining unaffiliated. Occupancy rate advantages accrue to brand-affiliated hotels across all segments in nonprimary markets and among mid-price and upscale hotels in primary markets. Brands, therefore, largely maintain their consistent occupancy rate advantages after our methodological controls. However, ADR advantages accrue to unaffiliated hotels only in nonprimary markets and then only in the mid-price and upscale segments in those markets. The ADR advantages of unaffiliated hotels seen in other studies and in the overall sample appear to be market specific and do not exist within primary markets.

These somewhat uneven results raise the issues of risk and return. Markowitz (1952), Fama and McBeth (1973), and Black (1993) have each provided theory and evidence showing that there is a positive relationship between risk and return, where risk is measured as the variance of the return, and investors rank preferences within the context of preferring higher mean returns and lower variances of returns. The results in Exhibits 1 and 2 open the question of the relative risk connected with affiliation versus that of remaining unaffiliated. For example, we found that the average RevPAR difference between unaffiliated and affiliated hotels is generally insignificantly different from 0 across market segments and market types. However, if the variance of RevPAR is significantly lower for affiliated hotels compared with unaffiliated hotels, then both the investor or owner of an affiliated hotel and the brand-owning corporation are better off by making a deal. The hotel investor and the brandowning corporation will benefit from the mutual reduction in risk. As the variance of performance measures is also important for investment, brand equity, and growth strategies, we compared the difference in variance for each of the performance measures for the affiliated hotels and unaffiliated hotels in our matched-pair sample. The results are shown in Exhibit 3. We use the Levene statistic to assess the homogeneity of the variances across the two sets of matchedpair hotels.

In earlier studies, such as in O'Neill and Carlback (2011), unaffiliated hotels were shown to have consistently higher variances of ADR, occupancy rates, and RevPARs. Similarly, our results categorized by both market segment and market type show that for nonprimary markets, unaffiliated hotels exhibit higher standard deviations in ADR, occupancy rates, and RevPARs when compared with brandaffiliated hotels. ${ }^{2}$ However, among hotels in primary markets, the results vary considerably. The luxury branded 
Exhibit 2:

Test of Mean Difference in ADR, Occupancy, and RevPAR for Brand-Affiliated and Unaffiliated Hotel Properties by Segment and Market Type (Matched Sample).

\begin{tabular}{|c|c|c|c|c|c|}
\hline \multirow[b]{2}{*}{ Segment } & \multirow[b]{2}{*}{ Market Type } & \multirow[b]{2}{*}{$n$} & \multicolumn{3}{|c|}{ Mean Difference, Unaffiliated - Affiliated } \\
\hline & & & ADR (US\$) & Occupancy (\%) & RevPAR (US\$) \\
\hline Budget & Nonprimary & 10 & -11.94 & 10.32 & -0.33 \\
\hline Economy & Nonprimary & 23 & -14.57 & $-7.85 * * *$ & -15.55 \\
\hline Mid-Price & Nonprimary & 604 & $4.53 * * *$ & $-6.82 * * *$ & -1.93 \\
\hline Upscale & Nonprimary & 1,014 & $18.34 * * *$ & $-6.26 * * *$ & 5.08 \\
\hline Luxury & Nonprimary & 352 & 21.99 & $-5.04 * * *$ & 6.49 \\
\hline Budget & $\begin{array}{l}\text { Primary } \\
\text { Primary }\end{array}$ & $\begin{array}{l}15 \\
22\end{array}$ & $\begin{array}{l}10.71 \\
-3.57\end{array}$ & $\begin{array}{r}-10.27 \\
6.33\end{array}$ & $\begin{array}{l}1.72 \\
0.55\end{array}$ \\
\hline Mid-Price & Primary & 153 & 2.42 & $-7.37 * * *$ & -3.17 \\
\hline Upscale & Primary & 76 & -4.97 & $-8.54 * * *$ & $-14.12^{* * *}$ \\
\hline Luxury & Primary & 204 & $11.4 \mid$ & -2.12 & 3.38 \\
\hline
\end{tabular}

Note. The standard errors used to compute the test statistics and significance levels were adjusted for correlation within each matched pair using the Newey-West procedure (Newey \& West, 1987), as modified for use in a panel data set using the procedure of Williams (2000). Note the small sample size for the budget and economy segments (shaded). We present these two segments for consistency only. ADR = average daily room rate; RevPAR = revenue per available room.

$* * * p<.001$.

\section{Exhibit 3:}

Test of Difference in Variance of ADR, Occupancy, and RevPAR for Brand-Affiliated and Unaffiliated Hotel Properties (Matched Sample).

\begin{tabular}{|c|c|c|c|c|c|c|c|c|c|c|c|}
\hline \multirow[b]{3}{*}{ Segment } & \multirow[b]{3}{*}{ Market Type } & \multirow[b]{3}{*}{$n$} & \multicolumn{9}{|c|}{ Standard Deviation } \\
\hline & & & \multicolumn{3}{|c|}{ ADR } & \multicolumn{3}{|c|}{ Occupancy } & \multicolumn{3}{|c|}{ RevPAR } \\
\hline & & & $\begin{array}{l}\text { Unaffiliated } \\
\text { (US\$) }\end{array}$ & $\begin{array}{l}\text { Affiliated } \\
\text { (US\$) }\end{array}$ & $\operatorname{Pr}>F(\%)$ & $\begin{array}{c}\text { Unaffiliated } \\
(\%)\end{array}$ & $\begin{array}{c}\text { Affiliated } \\
(\%)\end{array}$ & $\operatorname{Pr}>F(\%)$ & $\begin{array}{l}\text { Unaffiliated } \\
\text { (US\$) }\end{array}$ & $\begin{array}{c}\text { Affiliated } \\
\text { (US\$) }\end{array}$ & $\operatorname{Pr}>F(\%)$ \\
\hline Budget & Nonprimary & 10 & 5.12 & 8.38 & 34.56 & 17.48 & 7.94 & 5.26 & 7.26 & 5.26 & 17.13 \\
\hline Economy & Nonprimary & 23 & 20.81 & $4 I .51$ & 0.01 & 11.08 & 9.88 & 38.40 & 13.45 & 30.08 & 0.01 \\
\hline Mid-Price & Nonprimary & 604 & 21.37 & 17.14 & 0.05 & 16.17 & 14.66 & 2.38 & 17.62 & 15.60 & 4.28 \\
\hline Upscale & Nonprimary & 1,014 & 42.97 & 22.63 & 0.01 & 15.60 & 14.05 & 0.21 & 27.02 & 19.46 & 0.01 \\
\hline Luxury & Nonprimary & 352 & 109.77 & 74.28 & 3.86 & 15.20 & 11.48 & 0.01 & 56.95 & 46.50 & 6.79 \\
\hline Budget & Primary & 15 & 5.71 & 4.31 & 40.39 & 12.68 & 6.98 & 5.46 & 4.78 & 3.90 & 42.59 \\
\hline Economy & Primary & 22 & 6.51 & 3.49 & 1.50 & 25.75 & 7.30 & 0.01 & 11.05 & 2.74 & 0.01 \\
\hline Mid-Price & Primary & 153 & 32.19 & 32.79 & 89.10 & 18.46 & 15.35 & 1.38 & 37.26 & 31.97 & 27.35 \\
\hline Upscale & Primary & 76 & 51.82 & 66.36 & 19.72 & 15.01 & 12.80 & 18.85 & 51.21 & 64.23 & 24.95 \\
\hline Luxury & Primary & 204 & 59.62 & 128.46 & 0.89 & 13.33 & 13.01 & 82.44 & 51.77 & 91.57 & 2.48 \\
\hline
\end{tabular}

Note. The small sample size for the budget and economy segments (shaded). We present these two segments for consistency only. ADR = average daily room rate; RevPAR = revenue per available room.

properties, in particular, have a significantly higher standard deviation for ADR and RevPAR. Likewise, in the midprice segment the standard deviation of the occupancy rate of unaffiliated properties is significantly greater than that of the branded properties. These findings again suggest that results reported in previous studies do not always apply to specific market segments or market types. As was the case with the differences in performance, variance differences are not consistent across market type and market segment.

\section{Conclusion and Discussion}

\section{Summary}

Similar to O'Neill and Carlback (2011) but using a longer time horizon and a matched sample approach, we found significant ADR advantages overall for unaffiliated hotels and significant occupancy rate advantages for affiliated hotels. However, these advantages offset each other, and we found no significant differences in the two groups' 
RevPAR. Furthermore, when the results are categorized according to market type and market segments, we find a much different depiction of the performance differences of branded and unaffiliated properties. The occupancy rate advantage of affiliated hotels is still apparent in nonprimary markets but is found only among the mid-price and upscale segments in primary markets. Unaffiliated hotels and brand-affiliated hotels have significantly different ADRs for midscale and upscale hotels in nonprimary markets only. Finally, a RevPAR advantage exists for brandaffiliated hotels for the upscale segment in the primary markets only. In sum, in contrast to previous studies, our analysis shows that any discussion of performance advantages attributed to brand-affiliated versus unaffiliated hotels must recognize that these performance differentials are not consistent across market price segments and especially across market types.

\section{Discussion}

Our results add considerably to the current body of work relating to the competitive landscape facing brand-affiliated hotels and unaffiliated hotels. The results here provide evidence that brand-affiliated hotels show clear, significant, and fairly consistent occupancy rate advantages across both market types and most segments. We can infer that the distribution channel management systems, loyalty programs, and corporate and group business sales programs of brandaffiliated hotels are able to produce a significantly higher number of rooms sold regardless of the market size and market segment. This is evidence that within these markets and segments, brand equity as measured by the propensity to produce higher sales through higher occupancy rates in a competitive market environment can be statistically attributed to brand-owning hotel companies.

There is one exception to our findings in this regard. Among hotels in primary markets in the luxury segment, we found no significant evidence of an occupancy rate advantage accruing to brand-affiliated hotels. Consider that in this particular market type and segment, demand may show the signs of a more even playing field between branded hotels and unaffiliated properties. The factors likely contributing to this are (a) corporate and group business will likely provide the smallest boost to a luxury hotel's total demand, (b) consumers of luxury properties in these markets are likely to have higher incomes and tend to be more open to the bespoke experiences of unaffiliated hotels, and (c) the search costs for these well-known independent properties are likely to be lower than most other unaffiliated hotels as they generally have more well-established web presences, leading to less uncertainty regarding the quality of unaffiliated hotels vis-à-vis brand-affiliated hotels. These factors may tend to erode the potential for brand-owning hotel companies to create an occupancy rate differential generated by brand equity within the luxury segment in primary markets.

We also find that the ADR advantage of unaffiliated hotels, proposed by earlier studies as a pervasive factor, is now only evident in the smaller nonprimary markets and only for hotels in the mid-price and upscale segments of the market. In the primary markets, neither brand-affiliated hotels nor unaffiliated hotels show consistent rate advantages. This suggests that these denser, more agglomerated markets have different market pricing dynamics and competitive conditions as compared with the smaller nonprimary markets. For example, consumers in primary markets may be more informed about properties in primary markets than those in nonprimary markets so that brand recognition may be less important in primary markets. One competitive dynamic that distinguishes primary markets is that we are likely to find a full range of brands and multiple products from each of their brand family. As a result, brands compete more effectively across the range of market segments. This rate parity is also circumstantial evidence that unaffiliated hotels may follow the pricing patterns of affiliated hotels much more closely in primary markets as opposed to nonprimary markets, leading to a much more homogeneous pricing landscape across all market segments in primary markets.

This same competitive dynamic explains another dimension of the brand affiliation story, namely, rate and occupancy variance. In every segment among hotels in the nonprimary markets, brand-affiliated hotels have a significantly lower ADR and occupancy rate variance. As brands have corporate and other contract business that drives occupancy more consistently from loyalty programs and their web channels, demand and rates in their hotels will, on average, show much more stability.

In short, our results indicate that brands have a compelling story to tell owners who are considering entering into brand affiliation in a nonprimary market: "We will provide you with significantly higher occupancy and do so within the environment of a significantly lower variance, or risk, in both ADR and occupancy rate." Owners considering investing in these markets seem well advised to affiliate with a brand, and the product positioning strategies of brands within these segments seem most likely to provide continued growth advantages for hotel brands.

However, according to our results, this narrative is much less compelling in primary markets. In these larger, more agglomerated markets, the competitive dynamics provide occupancy rate advantages in only the mid-price and upscale markets and provide no significant ADR advantage for brands in any market segment. In addition to "rate parity," brand-affiliated hotels no longer demonstrate a lower variance in ADR and occupancy rate. Among hotels in primary markets, statistically significant lower occupancy rate variances are evident in only the mid-price segment, 
whereas in other segments neither ADR nor occupancy rate variances are statistically different. Indeed, in the luxury segment, rate variances are actually higher among brandaffiliated hotels. Our results suggest that major hotel brandowning companies may need to reevaluate their growth and product positioning strategies in primary markets and especially among hotels in the luxury segment. Although over the last 5 years there has been development of new brand products in the upscale segment characterized by a personalized and distinctive guest experience, these hotel companies should also consider developing more personalized brand products in the mid-price and luxury segments.

\section{Conclusion}

Our study is focused on the consumer's response to brand advantages in the various market segments and market types. The consumer's assessment of price preferences of a brand-affiliated property versus an unaffiliated hotel is evidenced here by ADR advantages for the unaffiliated properties. In contrast, the brands' ability to attract more customers through their distribution channel strategies and corporate sales programs is evidenced here through the consistent advantages accruing to brand affiliation in higher occupancy rates. Although we have shown that these advantages are sensitive to both market type and market segment, this does not rule out other brand advantages that may be more pervasive. Brands may have cost advantages related to economies of scope and scale that we do not address. This may lead to higher NOIs for brand-affiliated hotels as compared with their unaffiliated matched property.

However, as discussed, brand affiliation is not inexpensive. The higher costs imposed by management contracts and franchise agreements will tend to offset any higher income created by scale and scope advantages. Our study is limited in this dimension as it does not extend into the NOI dimension. Further research is necessary to see whether brand size and scope deliver consistent cost advantages large enough to compensate owners fully for the costs associated with brand affiliation and will then deliver significantly higher NOIs. These cost advantages may then provide additional information relevant to the investment decision of owners in a complementary manner to those motivated by the consumer side of the value decision reported here.

\section{Declaration of Conflicting Interests}

The author(s) declared no potential conflicts of interest with respect to the research, authorship, or publication of this article.

\section{Funding}

The author(s) received no financial support for the research, authorship, or publication of this article.

\section{Notes}

1. The size of brand-affiliated hotels exceeds unaffiliated hotels by 7.71 rooms, on average, in the sample.

2. Note the small sample size for the budget and economy segments. We present these two segments for consistency only.

\section{References}

Aaker, D. A. (1991). Managing brand equity. New York, NY: Free Press.

Aaker, D. A. (1996). Building strong brands. New York, NY: Free Press.

Alba, J. W., \& Hutchinson, J. W. (1987). Dimensions of consumer expertise. Journal of Consumer Research, 13, 411-454.

Anselmsson, J., Bondesson, N. V., \& Johansson, U. (2014). Brand image and customers' willingness to pay a price premium for food brands. Journal of Product \& Brand Management, 23(2), 90-102.

Black, F. (1993). Beta and return. Journal of Portfolio Management, 20, 8-18.

Blal, I., \& Sturman, M. (2014). The differential effects of the quality and quantity of online reviews on hotel room sales. Cornell Hospitality Quarterly, 55, 365-375.

Brooking, A. (1997). Management of intellectual capital. Long Range Planning, 30, 364-365.

Chen, M. J. (1996). Competitor analysis and inter-firm rivalry: Towards a theoretical integration. Academy of Management Review, 21, 100-134

Chen, M. J., Su, K. H., \& Tsai, W. (2007). Competitive tension: The awareness-motivation-capability perspective. The Academy of Management Journal, 50, 101-118.

Combs, J. G., \& Ketchen, D. J., Jr. (1999). Can capital scarcity help agency theory explain franchising? Revisiting the capital scarcity hypothesis. The Academy of Management Journal, 42, 96-207.

Damonte, L. T., Rompf, P. D., Bahl, R., \& Domke, D. J. (1997). Brand affiliation and property size effects on measures of performance in lodging properties. Journal of Hospitality Research, 20, 1-16.

de Chernatony, L., \& McDonald, M. (2003). Creating powerful brands in consumer, service and industrial markets. Oxford, UK: Butterworth-Heinemann.

Doyle, P. (2002). Marketing management and strategy. Harlow, UK: Pearson Education.

Fama, E., \& McBeth, J. (1973). Risk, return, and equilibrium: Empirical tests. Journal of Political Economy, 81, 607-636.

Freedman, M. L., \& Kosová, R. (2012). Agglomeration, product heterogeneity and firm entry. Journal of Economic Geography, 12, 601-626.

Hanson, B., Mattila, A. S., O’Neill, J. W., \& Kim, Y. (2009). Hotel rebranding and rescaling. Cornell Hospitality Quarterly, 50, 360-370.

Heckman, J. J., Ichimura, H., \& Todd, P. E. (1997). Matching as an econometric evaluation estimator: Evidence from evaluating a job training programme. Review of Economic Studies, 64, 605-654.

Heckman, J. J., Ichimura, H., \& Todd, P. E. (1998). Matching as an econometric evaluation estimator. Review of Economic Studies, 65, 261-294. 
Huang, R. D., \& Stoll, H. R. (1996). Dealer versus auction markets: A paired comparison of execution costs on NASDAQ and the NYSE. Journal of Financial Economics, 41, 313-357.

HVS. (2014, Fall). 2014 United States hotel franchise fee guide. Global Hospitality Report. HVS

Ingram, P., \& Baum, J. A. C. (1997). Chain affiliation and the failure of Manhattan hotels, 1898-1980. Administrative Science Quarterly, 42, 68-102.

Ismail, J. A., Dalbor, M. C., \& Mills, J. E. (2002). Using revPAR to analyze lodging-segment variability. Cornell Hotel and Restaurant Administration Quarterly, 43(4), 73-80.

Jones, J., \& Slater, J. S. (2003). What's in a name? Advertising and the concept of brands. New York, NY: M.E. Sharpe.

Kapferer, J. N. (1997). Strategic brand management-Creating and sustaining brand equity London term. London, England: Kogan Page.

Keller, K. L. (1993). Conceptualizing, measuring, and managing customer-based brand equity. Journal of Marketing, 57, 1-22.

Keller, K. L. (1998). Strategic brand management: Building, measuring and managing brand equity. Upper Saddle River, NJ: Prentice Hall.

Keller, K. L. (2002). Branding and brand equity. Cambridge, MA: Marketing Science Institute.

Keller, K. L., \& Lehmann, D. R. (2003). How do brands create value? Marketing Management, May/June, 27-31.

Kim, H.-B., \& Kim, W. G. (2005). The relationship between brand equity and firms' performance in luxury hotels and chain restaurants. Tourism Management, 26, 549-560.

Kim, H.-B., Kim, W. G., \& An, J. A. (2003). The effect of consumer-based brand equity on firms' financial performance. Journal of Consumer Marketing, 20, 335-351.

Krishnan, B. C., \& Hartline, M. D. (2001). Brand equity: Is it more important in services? Journal of Services Marketing, $15,328-342$.

Lafontaine, F. (1992). Agency theory and franchising: Some empirical results. Rand Journal of Economics, 23, 263-283.

Lane, V., \& Jacobson, R. (1995). Stock market reactions to brand extension announcements: The effects of brand attitude and familiarity. Journal of Marketing, 59, 63-77.

Love, A. S., Walker, B. H., \& Sutton, D. W. (2012). New option in hotel appraisals: Quantifying the revenue enhancement value of hotel brands. The Appraisal Journal, 80, 223-233.

Markowitz, H. (1952). Portfolio selection. The Journal of Finance, 7, 77-91.

Murray, K. B., \& Schlacter, J. L. (1990). The impact of services versus goods on consumers' assessment of perceived risk and variability. Journal of the Academy of Marketing Science, 18, 51-65.

Newey, W. K., \& West, K. D. (1987). A simple, positive semidefinite, heteroskedasticity and autocorrelation consistent covariance matrix. Econometrica, 55, 703-708.

O’Neill, J. W., \& Carlback, M. (2011). Do brands matter? A comparison of branded and independent hotels' performance during a full economic cycle. International Journal of Hospitality Management, 30, 515-521.
O’Neill, J. W., Mattila, A. S., \& Xiao, Q. (2006). Hotel guest satisfaction and brand performance: The effect of franchising strategy. Journal of Quality Assurance in Hospitality \& Tourism, 7(3), 25-39.

Prasad, K., \& Dev, C. S. (2000). Managing hotel brand equity: A customer-centric framework for assessing performance. Cornell Hotel and Restaurant Administration Quarterly, 41(3), 22-31.

Smith, K. G., Ferrier, W. J., \& Ndofor, H. (2001). Competitive dynamics research: Critique and future directions. Handbook of strategic management (pp. 315-361).

Srivastava, R. K., Shervani, T. A., \& Fahey, L. (1998). Marketbased assets and shareholder value: A framework for analysis. Journal of Marketing, 62, 2-18.

Steenkamp, J. E. M., Van Heerde, H. J., \& Geyskens, I. (2010). What makes consumers willing to pay a price premium for national brands over private labels? Journal of Marketing Research, 21, 1011-1024.

Washburn, J. H., Till, B. D., \& Priluck, R. (2004). Brand alliance and customer-based brand-equity effects. Psychology \& Marketing, 21, 487-508.

Williams, R. (2000). A note on robust variance estimation for cluster-correlated data. Biometrics, 56, 645-646.

Zeithaml, V. A. (1988). Consumer perceptions of price, quality, and value: A means-end model and synthesis of evidence. Journal of Marketing, 52(3), 2-22.

Zeithaml, V. A., Parasuraman, A., \& Berry, L. L. (1985). Problems and strategies in services marketing. Journal of Marketing, 49, 33-46.

Zhang, Y., Ye, Q., \& Law, R. (2011). Determinants of hotel room price: An exploration of travelers' hierarchy of accommodation needs. International Journal of Contemporary Hospitality Management, 23(7), 972-981.

\section{Author Biographies}

Steven A. Carvell is a professor of finance, Associate Dean for Academic Affairs, and Academic Director of the Leland C. and Mary M. Pillsbury Institute for Hospitality Entrepreneurship at the Cornell University School of Hotel Administration. His research is directed toward new approaches to hotel valuation and investment decisions.

Linda Canina is a professor of finance and Richard J. and Monene P. Bradley Director of Graduate Studies at the Cornell University School of Hotel Administration (SHA). Her research interests include asset valuation, corporate finance, and strategic management.

Michael C. Sturman is associate dean for faculty development, director of the Center for Hospitality Research, and the Kenneth and Marjorie Blanchard Professor of Human Resources at the Cornell University School of Hotel Administration (SHA). He also serves as an associate editor at the Journal of Applied Psychology. His research focuses on the prediction of individual job performance over time and the influence of compensation systems. 